CALIFORNIA AGRICULTURAL EXTENSION SERVICE Circular 137

July, 1947

\title{
GENERAL-CONTACT WEED KILLERS
}

A. S. CRAFTS

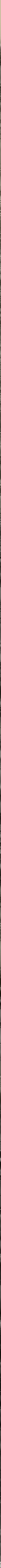




\section{GENERAL-CONTACT WEED KILLERS}

... are not selective. They destroy all kinds of vegetation-both weeds and crop plants.

- These herbicides are used to control unwanted plant growth along highways, rights-of-way, and fence lines, and around farm and industrial buildings. Sodium arsenite has been the chemical most commonly used for such purposes, but it is dangerous to humans and livestock. It is now being replaced by new sprays which are nonpoisonous, cheap, and easily applied.

- There are three types of general-contact herbicides:

1. Water-soluble materials, including common salts and corrosive chemicals, sodium chlorate, and salts of the phenol compounds.

2. Emulsions, made by combining water and oil. Additional toxic chemicals may be incorporated in either the oil or water base, or both.

3. Oils, including Diesel fuel, smudge-pot oil, stove oil, kerosene distillates, low-grade oils, proprietary weed-killer oils, and oils fortified by addition of phenol compounds or sulfur.

- There are many conditions under which general-contact sprays are effective, and a variety of spray materials which are suitable. For this reason, the present circular is concerned with giving an over-all picture of these different sprays and suggesting possible uses, without making hard and fast recommendations.

- Each grower will have to decide for himself which type of spray is best for his purpose, after he has studied the materials available and their advantages and disadvantages. 


\section{GENERAL-CONTACT WEED KILLERS}

\section{A. S. CRAFTS ${ }^{1}$}

HEAVY WEED GROWTH on roadsides and ditchbanks encourages crop pests and diseases and is a fire hazard. Weed growth can be dangerous on highways where it cuts off the motorist's view, and can also block off certain areas so that they are hard to reach. Mowing or disking is often used to remove such weeds, but there are many places where these fairly cheap methods are not satisfactory. In such cases, general-contact herbicides (weed killers) are commonly used.

General-contact weed killers are chemicals which kill all kinds of weeds and other plants. They are used to kill all unwanted growth in and around areas such as the following:

$\begin{array}{lll}\text { Roadsides } & \text { Parking areas } & \text { Farm buildings } \\ \text { Ditchbanks } & \text { Landing fields } & \text { Warehouses } \\ \text { Railroad rights-of-way } & \text { Firebreaks } & \text { Lumber yards } \\ \text { Fence lines } & \text { Highways } & \text { Irrigation structures } \\ \text { Dry yards } & \text { Pole lines } & \text { Industrial plants } \\ & \text { Billboards } & \end{array}$

General-contact sprays are not selective. They should never be used on crop plants.

For many years sodium arsenite solution has been the standard generalcontact spray. The railroads have used millions of gallons of this solution. The results in general have been good, but many livestock have been killed. New weed killers have been found which will work as well as arsenic but which are not poisonous to stock. These are taking the place of the poisonous chemicals.

The types of general-contact herbicides are:

1. Water-soluble chemicals, including common salts and corrosive chemicals (strong acids and alkalies), and salts of the phenol compounds.

2. Emulsions of water and oil in which additional oil- or water-soluble toxicants may be included.

3. Oils, including straight oils, and oils fortified with phenol compounds or sulfur.

This circular describes a number of these weed-killing materials and tells how to mix them. It also compares them so that the grower may judge which one will be best for his need.

\section{SPRAY SOLUTIONS MUST WET PLANTS THOROUGHLY}

In order to kill weeds, a contact spray must cover the plant surfaces and wet them thoroughly. Where grasses are part of the weed growth, the spray must creep down the stems and kill the plant crowns.

${ }^{1}$ Professor of Botany and Botanist in the Experiment Station. 
Spray chemicals may be mixed with either water or oil. Oil is a better spray base than water, for killing grasses, because it spreads and wets plant surfaces; water gathers into drops and rolls off. If a water spray solution is used, however, its wetting power can be increased by the addition of a wetting agent such as Dreft, Vel, Vatsol, Triton B1956, other Triton wetting agents, Oronite sodium sulfonates, and so forth. These materials are generally used in concentrations of about 0.1 per cent by weight. They are also useful in mixing emulsions.

\section{APPLICATION METHODS}

Several requirements must be met in the killing of weeds by sprays.

1. Sufficient toxicant must be applied to kill the bulk of vegetation and allow considerable excess for unevenness of application and differences in plant thickness.

2. The spray solution must be distributed so that the growing parts of the plants are completely covered.

3. Where vigorous grasses are present, the solution must creep down into the crowns to prevent renewal of growth by tillers.

The first two requirements may be met fairly readily by water solutions; the third requires oil or a solution having the properties of oils. Although wetting agents will greatly increase the spreading and wetting properties of sprays mixed only with water, or of emulsions, the high spreading and creeping qualities of oils can never be completely duplicated.

One way to increase the killing power of such sprays and emulsions is to increase concentration or volume, or both, until the necessary killing power is obtained. In some cases, this may be done rather easily; in others, the increase in dosage and hence in cost is such that use of oil alone is more economical. Only experiments under his own conditions can help the grower decide which of these two types of contact herbicide is more useful to him.

For satisfactory application of emulsions and sprays mixed with water alone, pressure at the nozzles should be 100 pounds or more. The nozzles should be spaced so that the spray fans meet at approximately the height of the vegetation. The boom should not be more than 18 inches above the vegetation; the full driving force of the spray is needed to wet the plants thoroughly. Most satisfactory results are obtained by using double coverage from different angles. Where application is made by hand, spraying should be slow and methodical so that all vegetation is thoroughly wet. If these precautions are observed, weeds should be controlled almost as effectively as where straight oil sprays are used.

The application methods given here apply to the water-soluble chemicals and to emulsions, since these mixtures involve special problems which do not apply to straight oil sprays.

(For detailed information on booms, nozzles, and spray equipment, write the Botany Division, Davis, for the mimeographed circular describing equipment for spraying weeds.) 


\section{WATER-SOLUBLE CHEMICALS}

There are two types of chemicals used in general-contact weed control that dissolve readily in water, and may be used in water solution as sprays. The first are well known, common chemicals; the second are the new phenol compounds. The sodium or ammonium salts of these phenol compounds may be used directly in water solutions.

In selecting a water-soluble chemical for weed control, several factors should be considered: (1) availability; (2) ease of use; (3) toxicity, as it relates to cost, dosage, and effectiveness; (4) hazards (poison, fire, and corrosion of equipment).

Common chemicals. These include: sodium chloride, calcium chloride, sodium chlorate, sodium arsenite, sodium hydroxide, "sodium borate, sulfuric acid, and many others less commonly used.

Although these chemicals have been widely used in general-contact sprays, they are not generally recommended because many of them are extremely dangerous to both humans and animals.

\section{Advantage:}

Some of these chemicals are manufacturers' by-products. If the grower is near the place of production, he may buy them at very low cost. For example, one such material is bittern.

\section{Disadvantages:}

Sodium arsenite: Livestock are attracted to this chemical and, as a result, many are killed annually. It is also dangerous to the spray operator, to pets, and to humans who may accidentally come into contact with it. It should only be used when such risks can be avoided.

Sodium chlorate: If spray containing this chemical dries on clothing, dead plants, wood, or other surfaces, it becomes highly inflammable, ignites by friction, and burns like gunpowder. It is hazardous to use as a spray.

Strong acids and alkalies are corrosive to machinery and dangerous to use.

New chemicals of high toxicity. Several new chemicals, the phenol compounds, have been recently introduced. They are extremely toxic to plants, and are now being used in place of the dangerous, more common chemicals, for general-contact sprays. Among them are: pentachlorophenol, dinitrocresol, dinitro secondary butyl phenol, dinitro secondary amyl phenol, and their salts. Most of these compounds are sold under trade names. Their content in such commercial products is shown on the labels. Examples of these products are: Sinox General and Dow General weed killers.

Sodium pentachlorophenate or sodium dinitro cresylate may be used as general-contact sprays in many situations if their toxicity is increased by acti- 
vating them with an acid salt such as ammonium sulfate, aluminum sulfate, or sodium bisulfate. These salts, at concentrations of 1 to 2 per cent (or even less when no grasses are present) will kill weeds that have been protected from full effects of sun and wind and consequently do not have thick leaf surfaces. Such protected areas are found, for example, in deep drainage ditches, shady orchards, and lathhouses.

The ammonium salt of dinitro secondary butyl phenol is so toxic that it will kill even grasses in their seedling stages. When used at concentrations of $\mathbf{0 . 5}$ per cent and over, with a good wetting agent, this herbicide has proved effective in killing mixed weeds on roadsides, ditchbanks, etc. On state highways in central California, fire strips sprayed with this material in April could be burned sufficiently within two to three weeks to provide adequate fire protection for adjoining crops and pastures.

\section{Advantages:}

1. The salts of the phenol compounds are soluble in water.

2. They are highly toxic; so little chemical is required that hauling is reduced to a minimum.

3. If used in large quantities, they can be bought at prices that compare favorably with those of fuel oils.

4. They have no serious poison hazard.

5. They form true solutions and require no agitation once they are dissolved.

6. They kill certain oil-resistant weeds, such as sweet fennel, yellow star thistle, mayweed, pineapple weed, and the like.

\section{Disadvantages:}

They are not economical for use on coarse, vigorous grasses, such as wild oats, foxtail, ripgut, and the like. On these weeds, an oil spray is necessary, because it will creep down the grasses and penetrate the crowns, where a water spray, unless applied in very large amounts, will run off.

All water-soluble herbicides require thorough application. Formulas for mixing them will be found on the labels.

\section{OIL SPRAYS}

A description of oil fractions and their toxic effects on weeds will be found on pages 12 to 16 . Growers who are not familiar with the properties of oils should consult this section before reading about oil sprays.

In contrast to sprays in water solution, oils wet plant surfaces readily and tend to spread as thin films and run down the stems. They penetrate the crowns of grasses where growing tissues that form new shoots are located. If an oil spray wets the tops of grasses thoroughly, the film may creep from 4 to 6 inches down the stems and kill all tissue from which new shoots might grow. This accounts for the satisfactory results usually obtained with Diesel and smudgepot oil sprays, both of which are standard materials for weed killing. 
The content of aromatic compounds in general-contact weed oils should be above 25 per cent and may be as high as $5^{\circ}$ per cent or more.

Diesel oil. To be used for making firebreaks along California highways, Diesel oil must meet the following specifications:

Specific gravity at $60^{\circ} \mathrm{F}$, not less than $27^{\circ}$ A.P.I.

Flash point (Pensky-Martens closed cup), not less than $15^{\circ} \mathrm{F}$.

Viscosity (Saybolt Universal) at $100^{\circ} \mathrm{F}$, not over $5^{\circ}$ seconds.

Distillation (9o per cent point), not over $610^{\circ} \mathrm{F}$.

Water and sediment, not over a trace.

Diesel meeting these specifications is readily available from oil dealers, and should be bought under the name of Diesel fucl oil.

\section{Advantages:}

Diesel combines a low acute toxicity with a medium chronic toxicity. Because it clings to the waxy plant surface, it wets plants easily and covers them well. It is very effective against mixed weeds, including grasses, and will kill completely even where growth is so dense that spray cannot be forced down into the bases of the plants. Being low in cost (in many areas), noncorrosive, and safe to handle, Diesel oil is an excellent herbicide for general weed control.

\section{Disadvantages:}

Because Diesel is relatively low in toxicity, a large volume per acre is required. This makes transportation costs relatively high. It also makes Diesel unfit for low-volume application by airplane unless fortified. Plants which are resistant to oil require too large an application to make use of Diesel economical. Because of its value as a fuel, widespread use of Diesel as a-weed killer seems unwise.

Smudge-pot oil. This may be used in place of Diesel because its properties are similar. It is often less refined and hence may be more toxic.

Stove oil. Although this oil may be used as a contact herbicide, it is largely limited to preëmergence spraying in cropped areas.

\section{Advantages:}

It may be used as a preëmergence spray in row crops even after crop plants have started breaking through the soil if the crops are tolerant of the oil. Some tolerant plants are carrots, celery, parsnips, and parsley. (For use of stove oil on carrot crops, see Extension Circular 136.)

\section{Disadvantages:}

It is lighter and less concentrated in chronic toxicants than Diesel oil, and is therefore less effective for general weed spraying, especially where there are large grasses. 


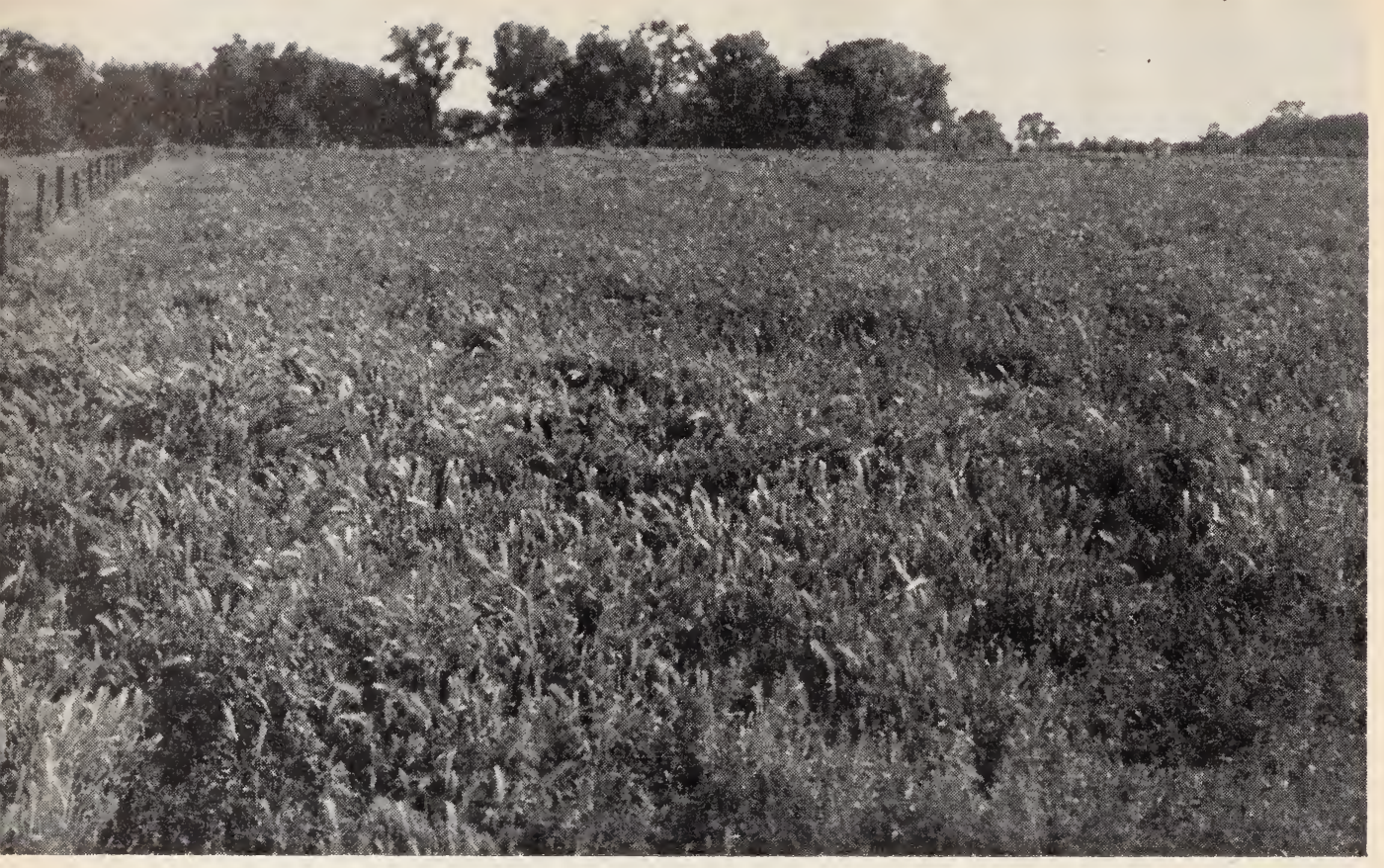

Fig. 1.-Unsprayed alfalfa field in which foxtail is beginning to spread.

Kerosene distillate. This is useful, if obtainable, as are other petroleum distillates in the same general boiling range. The gravity of such oils should range between $27^{\circ}$ and $38^{\circ}$ A.P.I. Below $27^{\circ}$ they are heavy and may be difficult to apply in cold weather; above $38^{\circ}$ they lack the persistent action of the chronic toxicants of heavier oil fractions. They are somewhat selective and are therefore ineffective on many oil-tolerant plants.

Low-grade oils. In certain oil-producing regions, low quality oils that are perfectly satisfactory for killing weeds may be bought from local refineries. Usually such oils are high in sulfur or aromatic compounds and may be unsuitable for use as lubricants or fuels. The properties that make them unfit for these uses may make them especially good weed killers from the standpoint of toxicity. Where such oils are available, they prove very useful in weed control.

Oil extracts. In the refining of medicinal oil, kerosenes, lubricating and other finer oils, solvent extraction is used to remove the more reactive unsaturates. Lighter grades of these by-products are recovered from the extract and used as paint thinners, cleaning fluids, and solvents. When these materials have been removed there may still remain a dark, foul-smelling substance of little commercial value. This residue is high in aromatic compounds and is extremely toxic to all plants. It is sold in limited quantities as a weed killer. (Avon Weed Killer, of the Tidewater Associated Oil Company, is an example.) 
Such oils are very useful as herbicides, but only a limited amount is available. They may be used to fortify Diesel oil when it has been so highly refined that it does not have enough killing action.

As demands for gasoline increase, stove, Diesel, and smudge-pot oils will be used for its manufacture, and new types of oils will be made available in their place. These new oils will be largely fractions resulting from the cracking operations used in gasoline manufacture and, if unrefined, may be higher in unsaturates than the present types. This should increase their toxicity. Nontillage programs in orchards, and an increased use of oil in weed control are creating a great demand for weed-killing oils. It seems likely that the large refiners will offer special products combining maximum spreading and wetting properties with a balanced toxicity sufficient to kill all weeds without wasting toxic compounds. Two such oils (Standard Weedkiller No. 2 and Shell Weedkiller No. 20) are now available.

Fortified oils. Oils of low toxicity may have their killing power increased by the addition of certain phenol compounds, or sulfur. They are then known as fortified oils. In addition to increasing the killing power, fortification provides extra toxicity where an oil is being used in emulsion or in low-volume application by airplane. It also makes oils more toxic to certain oil-tolerant weeds, such as sweet fennel, wild carrot, yellow star thistle, and mayweed. Most of these compounds are sold under trade names, with their content in the product shown on the labels.

Fig. 2.-Alfalfa field which was sprayed with fortified oil to remove annual weeds.

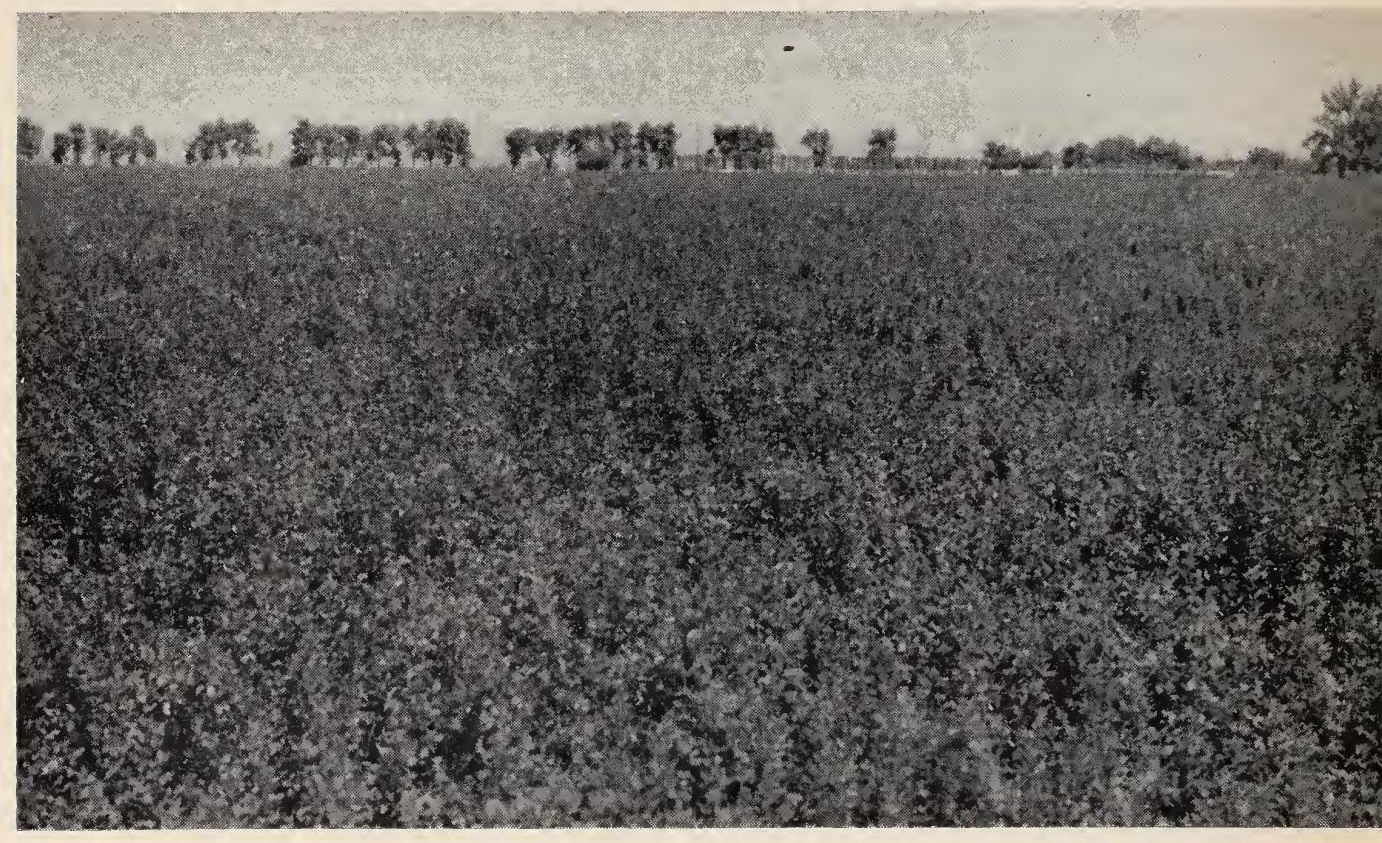


Pentachlorophenol and dinitro-cresol are about equally toxic in oil solution. For most purposes in the field, a $1 / 2$ per cent solution-roughly, 4 pounds per 100 gallons of oil-is enough; the same dosage rate applies to sulfur. Dinitro secondary butyl phenol (active ingredient in Dow General) is about three times as toxic, and only about $1 \frac{1}{3}$ pounds per 100 gallons is required. Dinitro secondary amyl phenol (active ingredient in Sinox General) has similar properties. Where oil-tolerant weeds, such as sweet fennel, yellow star thistle, and mayweed, predominate, the fortifying agent may be increased. (These special weed types, while resistant to oils, are very susceptible to 2,4-D, and dusts or sprays of this chemical may be used as separate treatments, preferably before the oil spray. The 2,4-D should not be combined with a toxic oil because the oil will defeat the purpose for which the 2,4-D is used. For further information on use of 2,4-D, see Extension Circular 133.)

In addition to the fuel oils, several less toxic oils are useful in weed control if they are fortified. Examples are wash and slop oils, reclaimed solvent and lubricating oils, old crankcase oil, and gas drip oil. In fact, the wetting and creeping properties of any oil may be combined with the high toxicity of a fortifying agent to produce a weed killer.

Viscosity, as it affects flow through nozzles and the spread of the oil on plants, is the most important factor in specifications of such oils. The viscosity of any herbicidal oil, as determined by the Saybolt Universal test at $100^{\circ} \mathrm{F}$, should not be over 5 o seconds.

\section{Advantages:}

Fortified oils are more toxic than straight fuel oils, and the volume used may be cut to the smallest amount which will give thorough coverage. In one case, where $15^{\circ}$ gallons of straight Diesel oil per mile was required to spray ditches in the Sacramento River delta, 75 gallons of Diesel containing 3 pounds of dinitro-cresol or 1 pound of dinitro secondary butyl phenol produced better results. In another instance, 14 gallons of fortified oil per acre was applied by airplane to kill small weeds in a field where onion bulbs had been planted for seed production. The field was too wet for application by ground sprayer, or for cultivation or hocing. A similar application has proved effective for eliminating small annual weeds in alfalfa. (For information on weed control in alfalfa, apply to the Botany Division, Davis, for the mimeographed circular describing the methods.)

Fortified oils are more rapid in their action than straight Diesel or heavier fuel oils. In spraying grass along the water line of irrigation ditches, for controlling the breeding of mosquitoes, only 24 hours were required before the ditch was restored to normal use. By killing quickly, fortified oils provide a longer period for burning. This makes them especially useful in killing weeds on highways where it is necessary to burn while the surrounding vegetation is still green.

Fortified oils will kill oil-tolerant weeds. They are useful for spot treat- 
ments on clumps of sweet femmel, poison hemlock, artichoke thistle, St. John's wort (Klamath weed), or other shallow-rooted perennials. They kill all weeds, including grasses, that come up through cracks in sidewalks, pavement, and concrete ditch lining. They are useful for treating Bermuda grass and similar pests in gravel walks and railroad ballast, and for treating individual weeds, such as dandelions, plantains, and chicory in lawns and permanent pastures.

Emulsions. The extreme toxicity of the recommended fortifying agents makes it possible to prepare fortified oils having much greater killing power than they have spreading ability. Such solutions may be applied in low volume from airplanes. Similar applications can be made by ground rigs if highpressure, small-orifice nozzles are used. Low-volume applications can also be made by vapo-dusting equipment, or by means of aerosol, smoke, or steam.

Although low-volume application is effective on small weed growth, more volume is required when plants have grown to the stage where they cover the soil and protect their own crowns. When this point has been reached, the fortified oil must be applied in emulsion. In fortified oil emulsions it is usually necessary to use wetting agents. Agitation in the spray tank is usually required because fuel-oil emulsions are not stable enough to hold throughout the period required for application.

Emulsion formulas. The formulas given below should be mixed on a weight basis. One hundred gallons of emulsion weighs roughly 800 pounds; 1 per cent would represent 8 pounds per 1 oo gallons; 1/2 per cent, 4 pounds; 1/4 per cent, 2 pounds; and $1 / 6$ per cent, $1 \frac{1}{3}$ pounds. Since Diesel oil weighs about 8 pounds per gallon, a satisfactory approximation can be made by adding the oil on a volume basis-2 per cent would be 2 gallons of oil and $9^{8}$ gallons of water; 6 per cent, 6 gallons of oil and 94 gallons of water.

A satisfactory emulsion may be made using:

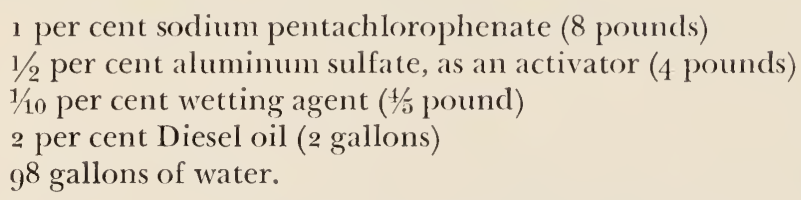

This formula has proved effective against broad-leaved annuals and such grasses as annual bluegrass and soft chess.

A better formula from the standpoint of cost includes:

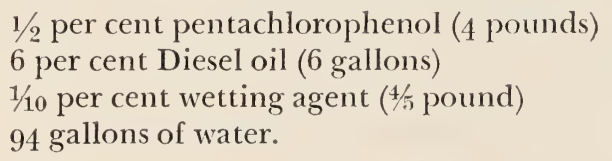

A similar emulsion can be made by using $1 / 6$, per cent dinitro secondary butyl phenol in place of the $1 / 2$ per cent pentachlorophenol. 
These formulas are satisfactory for broad-leaved weeds and grasses grown in sheltered locations. Where more vigorous grasses are present, the percentage of oil should be increased. Mixtures up to 25 per cent oil have been used against large, rapidly-growing wild oats, barley, and foxtail. Experience will determine the oil requirement and indicate the correct adjustment for the height and vigor of the vegetation. Such matters as the density of growth and the maturity with respect to possible tillering and late germination of additional seed must also be considered.

\section{Advantages:}

Emulsions kill oil-resistant weeds at a minimum cost. Chickweed, pineapple weed, and yellow star thistle have been killed in experimental tests in an onion crop where selective herbicides failed and where straight oil would have seriously harmed the crop. Although the emulsion injured the onions, they recovered rapidly. Yellow star thistle and mallow, both of which are resistant to Diesel, have been killed on roadsides by applications of emulsions.

The composition of emulsions may be adjusted to meet almost any condition. The oil content may be held to 1 or 2 per cent on tender weeds in orchards or in ditches, or may be increased to 15,20 , or 25 per cent in fighting heavy, vigorous infestations of grasses. Within this wide range there may be an appreciable saving of oil. And in all cases, oil-tolerant weeds are killed. As the oil content is raised above a level of about 25 per cent, a point of diminishing return is reached where the relative costs of oil, fortifying agent, and wetting agent must be balanced with the inconvenience of mixing and effectiveness of treatment.

Under most conditions, emulsions containing fortified oil are cheaper than straight oil because the toxicants are so much more effective than those present in oil alone. For example, the second formula on page 11 can be prepared for about one half the cost of a straight oil spray.

Use of emulsions cuts the cost of long-distance hauling of fuel oils. This becomes a real factor in regions far removed from oil refineries.

\section{Disadvantages:}

In using emulsions, the spray tank must be equipped with a mechanical agitator. Also, where large, vigorous grasses are present, results may never be quite so good as with oil because of the difference in creeping ability.

\section{PROPERTIES OF OILS ${ }^{2}$}

To use oil sprays in weed control, the grower must know something about oils and their effects on plants. In this way he will be able to choose the best oil for his own needs.

In the oil trade, all oils are described by sets of specifications. These are

${ }^{2}$ The four drawings are based on illustrations supplied through the courtesy of the Shell Oil Company, Incorporated, to whom acknowledgement is also made for editorial advice in connection with the preparation of material used in this section. 
either required by law or used by the manufacturer as a standard of quality for his own products. Every product must meet the specifications which its manufacturer has set up for it. These standards are intended to show a product's ability to do the job for which it was made. Certain oils now being tested as weed-killing sprays were not really intended for this use. Thus specifications listed for these oils do not necessarily show how well they will act as weed killers. There are no specifications for weedkilling oils. The only sure way to find out if an oil is useful as a weed killer is by tests in the field. Hence, in buying oils for weed killing, the grower will have to rely on the ability of the oil dealer to supply a satisfactory product.

This circular lists some of the words commonly used to describe oils and oil sprays, and tells what they mean. It also gives a simple account of the way in which oil is refined. The list should be helpful to the grower when choosing his oil sprays.

Refining. Two main processes are involved in oil refining: distillation and separation. An example of simple distillation is the boiling of a teakettle. The water in the kettle is heated to boiling temperature. At this point it turns to steam or vapor. If the steam

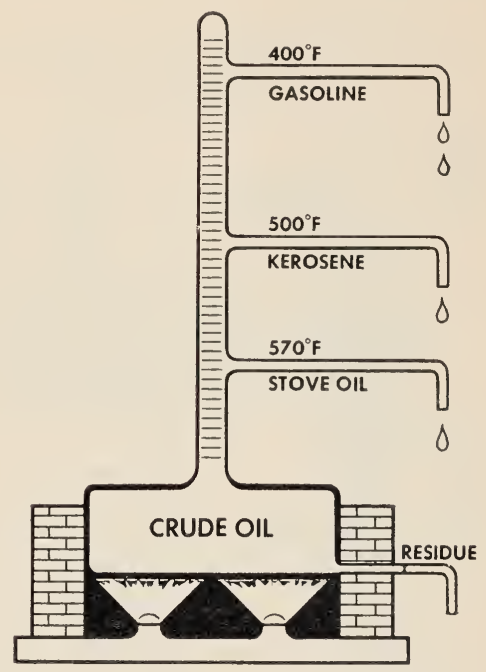

Fig. 3.-As the vapor passes up the tower, the part with the highest boiling point condenses and drops back. The fractions with the lowest boiling points are run off at the top.

touches a cold surface, it condenses. This condensed steam is a distillate. Since water has only one boiling point, the condensed steam is the only product resulting from the boiling of water.

Unrefined (crude) oil, on the other hand, is made up of many parts (fractions) which have different boiling points. The oil is put into a container, or tower, and heated. The fractions which have the lowest boiling point (gasoline) vaporize first and the vapors rise to the top where they condense. These fractions which evaporate quickly are the light (more volatile) ones. Other, less volatile fractions, such as stove oil and Diesel fuel, have higher boiling points, and condense later. Thus each batch of crude oil contains some gasoline, some stove oil, and some Diesel fuel, etc., and each fraction may be removed within its own boiling range. (See fig. 3.)

Distillates. The liquid oil fractions resulting from distillation are called distillates. Not all the materials in crude oil can be distilled; tars and asphalt are left. The distillates are not pure compounds but contain a mixture of all compounds which turn to vapor during distilling. Some of these are called 
unsaturated compounds. There are more of these unsaturated compounds in an oil such as Diesel fuel, that has not been highly refined, than there are in kerosene or spray oils that have received more treatment. When a refined oil is wanted, some or all of the unsaturated compounds may be separated from the oil by use of chemicals. Sulfur dioxide is one commonly used for this purpose.

It is the unsaturated compounds which are important in weed-killing oils. They determine, in part, how well the oil will kill plants. (See "Toxicity.")

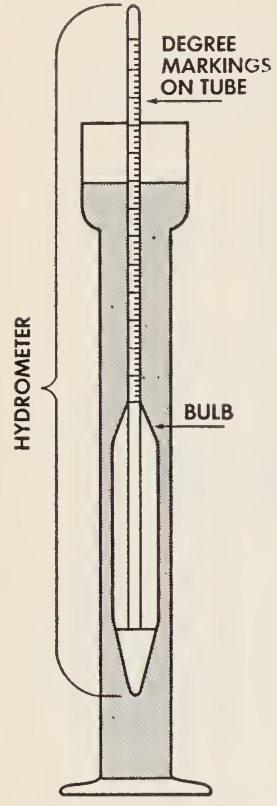

Fig. 4.-The hydrometer floats in oil. Gravity measurements are indicated on the tube.
Gravity. The gravity, or density of an oil has to do with its weight. It is expressed in degrees A.P.I. because the gravity of oils in the United States is determined by tests set up by the American Petroleum Institute. The gravity of an oil is found by use of an instrument called a hydrometer. This is a glass tube with degree markings on the side and a bulb at one end. (See fig. 4) The bulb floats in the oil sample to be tested, and the depth to which it sinks, as indicated by the marks on the tube, is a measure of the gravity of the oil. The bulb does not sink so far in heavy oils as in light ones. The degrees are marked on the tube in such a way that gravity readings of heavy oils are lower than those of light ones.

Gravity is important in choosing a weed-killing oil. Heavy oils, which fall below $38^{\circ}$ A.P.I., will kill crop plants as well as weeds. For use as a selective herbicide on crop plants, therefore, a weed-killing oil should not fall much below $38^{\circ}$ A.P.I.

Flash point. Flash point is a measure of the inflammability of an oil. One of the means for testing the flash point is the Pensky-Martens closed cup test. The oil is heated in a closed container, or cup. (See fig. 5.) A slide covers a small opening in the cup. This is opened at definite intervals, and a flame is passed over the oil. The temperature at which the oil ignites is its flash point.

Highly volatile oils ignite at fairly low temperatures. All gasolines flash at ordinary temperatures (for instance, $70^{\circ} \mathrm{F}$ ); in fact, they will flash at freezing temperature for water. From the standpoint of safety for the operator, it is dangerous to use gasoline for weed spraying. Only less volatile fractions, such as some of the thimners and solvents, are fairly safe to use. However, the spray operator must remember that all these products are inflammable. The spray mist and surrounding air may ignite and burn with great heat.

Viscosity. This relates to the flowing quality of an oil. To find the viscosity, 60 cc (about 2 ounces) of oil are put into an instrument called the Saybolt 
Universal viscosimeter. The oil is heated to $100^{\circ} \mathrm{F}$. It is then timed as it runs through a small opening in the instrument. (See fig. 6.)

The viscosity of an oil to be used as a spray determines somewhat the amount of pressure needed, and the size of the spray orifices. The heavier oils will not break up into drops easily, nor flow as fast as will the lighter ones. Viscosity is also a factor in determining how much of the oil soaks into the plant surfaces. A heavy oil will stay on the plant longer than will a lighter, more volatile one. Thus it may soak in in larger amounts and be more toxic. For use as a weed spray, an oil's viscosity should be about $5^{\text {o sec- }}$ onds or less.

Toxicity. An oil's toxic effect on plants depends in part on how volatile it is and on the amount of unsaturated compounds it contains. Oils vary in their toxicity. Some kill all plants; some are selective,

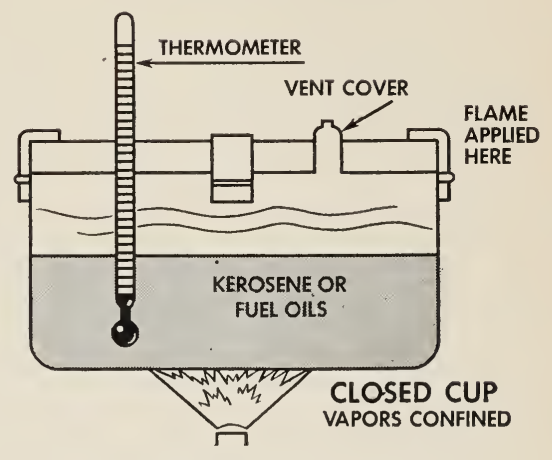

Fig. 5.-The closed cup test for determining the flash point. and kill only.weeds, leaving certain crop plants undamaged. Light unsaturated compounds cause a rapid burning of leaves called acute toxicity. Heavy unsaturated compounds injure the growing parts and cause a chlorosis (yellowing of leaves). This injury comes on much more slowly and is called chronic toxicity. Very light unsaturated compounds, such as those from gasoline stock, cause burning of the leaves. Injury is not complete, however, if the spray incompletely saturates the plant, because these oils may evaporate before all tissues are killed.

Unsaturated compounds of medium weight are very toxic to grasses and most weeds. They do not kill plants of the carrot family, except at high concentrations. They are usually found in unrefined petroleum distillates, such as stove oil, at concentrations between 20 and $3^{\circ}$ per cent. Heavy unsaturated compounds, such as those in Diesel and other heavy fuels, kill plants slowly by chronic toxicity. Crop plants as well as weeds are killed by such oils.

Fig. 6. - The viscosimeter operates on the principle shown below.

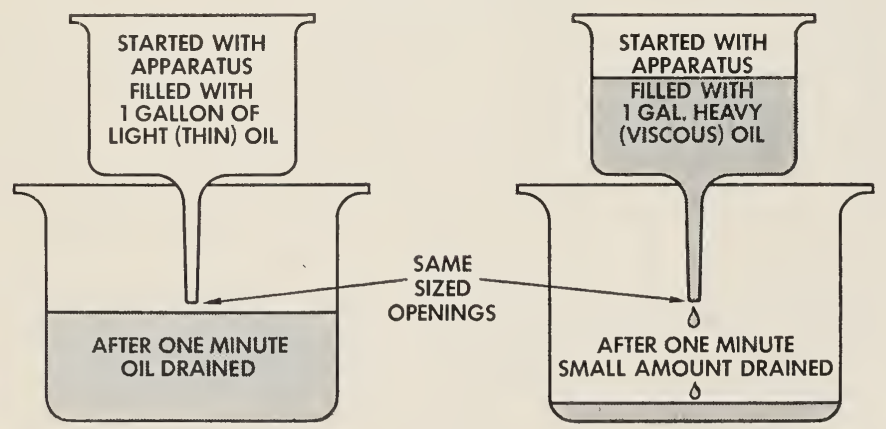




\section{OILS FOR WEED CONTROL}

Selective oil sprays are ones which do not damage certain oil-tolerant crop plants but kill many common weeds.

General-contact oil sprays kill all kinds of plants, both weeds and crops. They should contain enough toxicants to kill all plants sprayed.

Emulsions are physical mixtures of oils and water. Most emulsions have a water base in which droplets of oil are suspended.

Invert emulsions, however, have an oil base in which droplets of water are suspended. Weed-killing emulsions may have additional chemicals dissolved in either the oil or water, or both.

Fortified oils are oils which have had their toxicity increased. This is done by adding chemicals (fortifying agents) such as phenol compounds or sulfur. It usually costs less for these fortifying agents, per unit of toxicity, than for an amount of unfortified oil of equal toxicity. Fortified oils are used as generalcontact sprays. The oil itself acts mainly as a carrier for the toxic fortifying agent.

Oils serve two purposes in chemical weed control. They act as toxicants (killers) and as carriers. In selective weed oils, the toxicants (medium-weight unsaturated compounds) should be present at concentrations that kill weeds without killing crops. For carrots, this concentration may be fairly high (around 25 per cent). To spray safely in flax, it should be considerably lower, and for onions, still lower. The oil should be so light that all toxicity is of the acute type. This means that it should have a gravity above $38^{\circ}$ A.P.I. (Shell Weedkiller No. 10, for example, has a gravity of about $43^{\circ}$ A.P.I.) This guarantees that the toxicity is acute. At the same time, such oils evaporate fast, so that the oil flavor soon leaves the crops.

The nontoxic part of the selective oil acts as a carrier for the toxic parts. It cannot be replaced by water because the selective toxicants are oils and will not act in emulsion. Also, the wetting properties of straight oil are required to kill grasses in the crop.

Oil is a better carrier than water because it has a low surface tension and high wetting ability. This means that instead of running off the plants as water does, the oil creeps over them. In doing this, it soaks into the growing parts and kills the tissues. This wetting ability is especially important where the oil is to be used on weed growth containing rank, vigorous grasses.

Coöperative Extension work in Agriculture and Home Economics, College of Agriculture. University of California, and United States Department of Agriculture coöperating. Distributed in furtherance of the Acts of Congress of May 8, and June 30, 1914. B. H. Crocheron, Director, California Agricultural Extension Service. 